Abstracta Iranica Abstracta Iranica

Revue bibliographique pour le domaine irano-aryen

Volume 28 | 2007

Comptes rendus des publications de 2005

\title{
Afsaneh, Short Stories by Iranian Women. Londres, Saqi Books, 2005, 200 p.
}

\section{Leili Anvar-Chenderoff}

\section{(2) OpenEdition}

1 Journals

Édition électronique

URL : http://journals.openedition.org/abstractairanica/21421

DOI : 10.4000/abstractairanica.21421

ISSN : 1961-960X

\section{Éditeur :}

CNRS (UMR 7528 Mondes iraniens et indiens), Éditions de l'IFRI

\section{Édition imprimée}

Date de publication : 15 mai 2007

ISSN : 0240-8910

Référence électronique

Leili Anvar-Chenderoff, «Afsaneh, Short Stories by Iranian Women. Londres, Saqi Books, 2005, 200 p. », Abstracta Iranica [En ligne], Volume 28 | 2007, document 363, mis en ligne le 18 septembre 2007 consulté le 25 septembre 2020. URL : http://journals.openedition.org/abstractairanica/21421 ; DOI : https://doi.org/10.4000/abstractairanica.21421

Ce document a été généré automatiquement le 25 septembre 2020.

Tous droits réservés 


\title{
Afsaneh, Short Stories by Iranian Women. Londres, Saqi Books, 2005, $200 \mathrm{p}$.
}

\author{
Leili Anvar-Chenderoff
}

1 Recueil de nouvelles de femmes iraniennes traduites en anglais. L'A. n'est pas un spécialiste de la question et l'on notera donc quelques erreurs et approximations dans la préface (par ex., p. 7, l'assertion selon laquelle il n'est pas fait mention d'écrivains femmes en littérature persane avant 1931, à part Schéhérazade!). La sélection des nouvelles est très classique et visiblement faite à partir des anthologies de nouvelles de femmes qui circulent en Iran aujourd'hui (aucune référence aux éditions persanes des textes). Elle représente un bon panorama de la production actuelle. Mais la traduction en anglais est loin de rendre justice à la force stylistique des originaux. Est-ce parce que le traducteur n'est pas de langue maternelle anglaise? Notes biographiques minimalistes en fin de recueil.

INDEX

Thèmes : 11.1.2. Littérature persane moderne

\section{AUTEURS}

\section{LEILI ANVAR-CHENDEROFF}

INaLCO - Paris 